\title{
TREATMENT OF TRADITIONAL ETHANOL FERMENTATION WASTE WITH ELECTROLYSIS METHOD FOR DECREASING COD AND SULFIDE
}

\author{
Dimas Eko Saputra ${ }^{1}$, Siti Fatimah ${ }^{2}$ \\ 1,2 Universitas Muhammadiyah Surakarta \\ Email: 1dimaseko23@gmail.com, ${ }^{2}$ sf120@ums.ac.id
}

(Naskah masuk: 17 November 2020, diterima untuk diterbitkan: 24 Juni 2021

\begin{abstract}
Ethanol is produced from molasses by a fermentation process. In Bekonang, ethanol manufacturingby a homescale industry so the waste just thrown away in free water then pollution occurs both in rivers and in paddy fields. Ethanol waste has very high chemical oxygen demand (COD) and contain high sulfide. Electrolysis that use for reduce leves COD dan Sulfide with electricity as main source for direct current flowing electricity (dc) to the anode and cathode. Electrolysis time 10,15,20,25 and 30 minutes and voltage variation 5, 10 and 15 volt. Based on data obtained in the test COD obtained optimum levels of $284.5 \mathrm{mg} / \mathrm{L}$ from the initial content of $586 \mathrm{mg} / \mathrm{L}$, at a time variation of 30 minutes and voltage 15 volt. The sulfide test obtained optimum levels of $0.0661 \mathrm{mg} / \mathrm{L}$ from the initial content of $0.305 \mathrm{mg} / \mathrm{L}$, at time variation of 25 minutes and a voltage of 15 volt.
\end{abstract}

Keywords: ethanol, chemical oxygen demand, sulfide, electrolysis

\section{PRELIMINARY}

The ethanol industry or commonly in their call as ciu, located in Sentul, Bekonang Village, Mojolaban Subdistrict, Sukoharjo Regency, is an industry that has to much effluents. Understanding ethanol according to(de Vasconcelos, 2015) Ethanol is commonly determined to be the chemical component ethanol or ethyl alcohol (de Vasconcelos, 2015). Whereas according to (Dalena et al., 2019)is an alcohol mainly produced from agricultural residues and it can be derived from fermentation of sucrose or simple sugars, coming from the biomass treatment (Dalena et al., 2019). In bekonang, ethanol is produced from molasses by a fermentation process. Molasses from sugarcane industry is it common raw material used in ethanol production due to its easy availability and low cost (Patel and Durgavati Vishwavidyalaya, 2018).

The ethanol manufacturing industry is a homescale industry so that the processing of the waste has not been properly processed. The waste is thrown away in free water and only a little is processed in the WWTP (Waste Water Treatment Plant) which does not function properly so that the smell of waste disturbs the surrounding environment. Not only smells, ethanol waste or the usual local residents call it badek also give effects in agricultural products whose commodities are rice in the surrounding environment can not grow optimally even up to crop failure.
Distillery effluent has very high biological oxygen demand (BOD), chemical oxygen demand (COD) and high BOD/COD ratio. The amount of inorganic substances such as nitrogen, potassium, phosphates, calcium, sulphates is also very high. These compounds have antioxidant properties which render them toxic to many microorganisms such as those typically present in wastewater treatment processes. Ethanol waste are acidic, have a brown colour, have a high content of organic substances and contain large amount of dark brown coloured molasses wastewater (MWW). The highly colored components of the effluent can block out sunlight from in rivers, lakes or lagoons which in turn decrease both photosynthetic activity and dissolved oxygen concentration affecting aquatic life (Patel and Durgavati Vishwavidyalaya, 2018).

To treat both organic and inorganic waste in this study we agreed to use the electrolysis method. Electrochemical technologies such as electrolysis have been successfully employed for the treatment of many wastewaters on an industrial scale. The electrical conductivity as well as salinity was decreased through the electrolysis procedure, because of the loss of electrolyte ions in the wastewater through the formation of compounds and its sedimentation. Most electrochemical processes use a couple of metallic electrodes, usually a relatively stable anode such as titanium and a relatively active cathode such as aluminum and iron (Chopra, Kumar Sharma and Kumar, 2011). 


\section{METHODOLOGY}

This research was conducted with the aim to determine the reduction of COD and Sulfide levels from ethanol liquid waste by using the electrolysis method. By using these methods, in this study there are two factors that are varied. The first factor is the variation of voltage $(5,10$ and 15 volts) and the second factor is the variation of electrolysis time $(10$, $15,20,25$ and 30 minutes).

\subsection{Time and place of sampling}

This research was conducted in OctoberDecember 2019 at the Chemical Engineering Laboratory, Muhammadiyah University, Surakarta. Ethanol waste sample was taken from one of the home industries in Bekonang Village, Mojolaban District, Sukoharjo Regency, Central Java Province.

\subsection{Research tools}

The tools used in this study include; weigh bottle, burette, erlenmeyer, beaker, measuring cup, hotplate, measuring flask, suction rubber, watch glass, magnetic stirrer, glass stirrer, dropper pipette, measuring pipette, volume pipette, power supply, stopwatch, UV-Vis spectrophotomoter, scales analytic, cuvette, goblet, digestion vessel, heating block.

\subsection{Research materials}

Materials used in this study include; $\mathrm{Ag}_{2} \mathrm{SO}_{4}$, $\left(\mathrm{NH}_{4}\right)_{2} \mathrm{HPO}_{4}, \mathrm{HgSO}_{4}, \mathrm{H}_{2} \mathrm{O}, \mathrm{H}_{2} \mathrm{SO}_{4}, \mathrm{HCl}, \mathrm{NaOH}$, $\mathrm{K}_{2} \mathrm{Cr}_{2} \mathrm{O}_{7}$, distilled water, N,N dimetil-pfenilendiamin oxalic, $\mathrm{FeCl}_{3.6} \mathrm{H}_{2} \mathrm{O}, \mathrm{Kl}, \mathrm{I}_{2}$, $\mathrm{Na}_{2} \mathrm{~S}_{2} \mathrm{O}_{3} .5 \mathrm{H}_{2} \mathrm{O}$, kanji, salicyic acid, zinc acetate, $\mathrm{Na}_{2} \mathrm{~S} .9 \mathrm{H}_{2} \mathrm{O}$

\subsection{Work Procedures}

\subsubsection{Dilution of liquid waste}

Ethanol waste taken before treatment is diluted using water in a ratio of 1:500

\subsubsection{Testing of initial waste levels}

Ethanol waste that has been taken is tested by COD and Sulfide parameter levels as comparison levels after treatment

\subsubsection{Electrolysis}

After conducting the initial testing, as much as $1000 \mathrm{ml}$ of waste is put into the beaker. Then the aluminum electrode is installed as the anode on the pole (-) and the copper electrode as the cathode is mounted on the pole (+). The two electrodes were inserted into a beaker containing a waste sample with a distance of $5 \mathrm{~cm}$, the power supply was turned on with a voltage variation of $5,10,15$ volts and with a variation of treatment time of 10, 15, 20, 25 and 30 minutes in each sample. Then each sample with a different voltage and treatment time is carried out the COD and sulfide analysis process.

\subsubsection{COD analysis}

\subsubsection{Making digestion solution}

Mix $1.022 \mathrm{~g}$ of $\mathrm{K}_{2} \mathrm{Cr}_{2} \mathrm{O}_{7}$ that has been dried at $150^{\circ} \mathrm{C}$ for 2 hours then add $500 \mathrm{ml}$ of distilled water, add $167 \mathrm{~mL}$ of concentrated $\mathrm{H}_{2} \mathrm{SO}_{4}$ and $33.3 \mathrm{~g}$ of $\mathrm{HgSO}_{4}$ and cool at room temperature then dilute to $1000 \mathrm{~mL}$.

\subsubsection{Manufacture of sulfideic acid reagents}

Dissolve $10.12 \mathrm{~g}$ of $\mathrm{Ag}_{2} \mathrm{SO}_{4}$ crystal into 1000 $\mathrm{mL}$ concentrated $\mathrm{H}_{2} \mathrm{SO}_{4}$ then stir until dissolved.

\subsubsection{Analysis of COD levels}

Measurement of COD levels using the closed reflux method, where the sample was added with a digestion solution and sulfuric acid reagent solution which was first refluxed at a temperature of $150^{\circ} \mathrm{C}$ for 2 hours.

\subsubsection{Sulfide analysis}

\subsubsection{Test preparation}

Mix $1.022 \mathrm{~g}$ of $\mathrm{K}_{2} \mathrm{Cr}_{2} \mathrm{O}_{7}$ that has been dried at $150^{\circ} \mathrm{C}$ for 2 hours then add $500 \mathrm{ml}$ of distilled water, add $167 \mathrm{~mL}$ of concentrated $\mathrm{H}_{2} \mathrm{SO}_{4}$ and $33.3 \mathrm{~g}$ of $\mathrm{HgSO}_{4}$ and cool at room temperature then dilute to $1000 \mathrm{~mL}$.

\subsection{Standardization of sodium thiosulfate solution with potassium bi-odate}

Dissolve $2 \mathrm{~g}$ of $\mathrm{Kl}$ in $300 \mathrm{ml}$ size erlenmeyer ash with $100 \mathrm{ml}$ of sulfide free water. Add $1 \mathrm{~mL}$ of $6 \mathrm{~N}$ sulfideic acid and add $20 \mathrm{~mL}$ of a standard solution of potassium bi-odate to an erlenmeyer containing Kl. Place for 5 minutes in a dark room and dilute to 300 $\mathrm{mL}$ then titar with sodium thiosulfate to light yellow color. Add $1 \mathrm{ml}$ of the starch indicator and titrate to the end point marked by the loss of blue.

\subsection{Manufacture of main liquor}

Weigh $3.75 \mathrm{~g}$ of sodium sulfide $\left(\mathrm{Na}_{2} \mathrm{~S} .9 \mathrm{H}_{2} \mathrm{O}\right)$ in a weighing bottle. Transfer quantitatively into a $500 \mathrm{~mL}$ volumetric flask and place it until the marking mark with sulfide free water. $(1 \mathrm{~mL}=1.00$ $\mathrm{mg}$ S2). Standardize the solution with iodometric titration

\subsection{Preparation of $100 \mathrm{mg}$ sulfide standard solution $\mathbf{S}^{2-}$ / $\mathbf{L}$}

Dilute $10 \mathrm{~mL}$ of $1000 \mathrm{mg}$ sulfide master solution $\mathrm{S}^{2-} / \mathrm{L}$ with sulfide free water into $100 \mathrm{~mL}$ measuring flask until the

\subsection{Manufacture of sulfide working solutions \\ Make a working solution series from the standard $10 \mathrm{mg} \mathrm{S}^{2-} / \mathrm{L}$ sulfide solution with 1 blank}


and at least 3 different levels in a $50 \mathrm{~mL}$ volumetric flask.

\subsubsection{Making calibration curves and measuring test samples}

\subsection{Making a calibration curve}

As much as $50 \mathrm{~mL}$ of sulfide-free water is put into a measuring flask then add $0.5 \mathrm{~mL} \mathrm{H}_{2} \mathrm{SO}_{4}$ and 3 drops of $\mathrm{FeCl}_{3}$ and mix, then wait for 5 minutes. Add $1.6 \mathrm{~mL}$ of diammonium hydrogen phosphate solution. This solution is used as a zero instrument. To the working solution series and blank add $0.5 \mathrm{~mL}$ of sulfideic-amine acid reagent and 3 drops of $\mathrm{FeCl}_{3}$ solution. The mixture is immediately converted slowly and wait for minutes. Add $1.6 \mathrm{~mL}$ of $\mathrm{HPO}_{4}$ $\left(\mathrm{NH}_{4}\right)$ solution, let stand until it forms a blue color.

\subsection{Test for sulfide content}

Put the test sample into a $50 \mathrm{~mL}$ volumetric flask and then dilute with sulfide free water to the pitch mark, add $0.5 \mathrm{~mL}$ of amine sulfideic acid reagent and $0.15 \mathrm{~mL}$ of $\mathrm{FeCl}_{3}$ solution. The mixture is immediately converted slowly. Add $1.6 \mathrm{~mL}$ of $2 \mathrm{HPO}_{4}$ $\left(\mathrm{NH}_{4}\right)$ solution then let stand for 10-15 minutes read and record the absorption of the test sample.

\section{RESULT AND DISCUSSION}

Wastewater can contain substances that are highly toxic to aquatic life and human populations. The pollutants may be dissolved or suspended in the water. Toxic contaminants, both organic and inorganic are carried by suspended particles and dissolved in the water, increasing the organic load and transporting hazardous chemical compounds (Burroughs and Burroughs, 2011).

Chemical Oxygen Demand (COD) is the chemical oxygen demand test (COD) determines, the oxygen required for chemical oxidation of organic matter with the help of strong chemical oxidant.The COD is a test which is used to measure pollution of domestic and industrial waste. The waste is measure in terms of required for oxidation of organic matter to produce $\mathrm{CO}_{2}$ and water (Candia-Onfray et al., 2018).

out Hydrogen Sulfide $\left(\mathrm{H}_{2} \mathrm{~S}\right)$ is a colorless, very poisonous gas flammable. This gas can cause bad effects for health. At low concentrations it can cause eye, nose or irritation esophagus, and for a long time can cause permanent effects like respiratory disorders, headache, and chronic cough. Even exposure to hydrogen sulfide in concentrations higher than 500 ppm can result in loss of consciousness and maybe death (Pakpahan, et al. 2015).
Tabel 1. the initial levels of COD and Sulfide

\begin{tabular}{ccc}
\hline Parameter & $\begin{array}{c}\text { Highest Level } \\
(\mathrm{mg} / \mathrm{L})\end{array}$ & $\begin{array}{c}\text { Pollution load } \\
(\mathrm{kg} / \text { ton })\end{array}$ \\
\hline BOD $_{5}$ & 100 & 1.5 \\
\hline COD & 300 & 4.5 \\
\hline TSS & 100 & 1.5 \\
\hline Sulfide (as S) & 0.5 & 0.0075 \\
\hline pH & \multicolumn{2}{c}{$6.0-9.0$} \\
\hline $\begin{array}{c}\text { Highest waste } \\
\text { discharge }\end{array}$ & $\begin{array}{c}15 \mathrm{~m}^{3} \text { per tonne of } \\
\text { tapioca products }\end{array}$ \\
\hline
\end{tabular}

To find out the effect of the treatment, two parameters of waste are used namely COD and sulfide. The following table shows the results of initial levels of ethanol liquid waste

Tabel 2. the initial levels of COD and Sulfide

\begin{tabular}{lccl}
\hline Sample & Unit & COD & Sulfide \\
\hline Initial & $\mathrm{mg} / \mathrm{L}$ & 586 & 0.305 \\
\hline Electrolysis & $\mathrm{mg} / \mathrm{L}$ & 284.5 & 0.0661 \\
\hline
\end{tabular}

At first the COD level was $586 \mathrm{mg} / \mathrm{L}$. After treatment, the waste COD level becomes $284.5 \mathrm{mg} /$ $\mathrm{L}$, so the effect given from this treatment is $51.45 \%$. For the initial comparison, the sulfide content of the ethanol waste is $0.305 \mathrm{mg} / \mathrm{L}$. After treatment using electrolysis the level changed to $0.0661 \mathrm{mg} / \mathrm{L}$, meaning that the effect given from this stage on sulfide levels was $78.32 \%$.

Tabel 3. the results of the analysis of the influence of voltage variations

\begin{tabular}{lllll}
\hline \multirow{2}{*}{ Parameter } & unit & \multicolumn{3}{c}{ Voltage (volt) } \\
\cline { 3 - 5 } & & 5 & 10 & 15 \\
\hline COD & $\mathrm{mg} / \mathrm{L}$ & 466.5 & 488 & 426.5 \\
\hline Sulfide & $\mathrm{mg} / \mathrm{L}$ & 0.029 & 0.033 & 0.017 \\
\hline
\end{tabular}

Table 3 is the result of electrolysis treatment with voltage variations with a testing time of 10 minutes. The COD and sulfide parameters occur irregularly from their initial levels. From this it is known that stress has a very significant effect on COD treatment. Among these variations (5 volts, 10 volts, 15 volts) the 10 volt voltage gives a less significant effect because the COD level becomes 488 $\mathrm{mg} / \mathrm{L}$ which means the level of decrease is $16.72 \%$. Whereas for 5 volt voltage there was a significant decrease to $466.5 \mathrm{mg} / \mathrm{L}$ which means that the level of reduction was $20.39 \%$. For the voltage of 15 volts, 
the greatest decrease occurred compared to 5 and 10 volts, which is $426.5 \mathrm{mg} / \mathrm{L}$, which means the rate of decrease is $27.21 \%$. As for the sulfide content, the greatest effect also occurs at a voltage of 15 volts until the sulfide level becomes $0.017 \mathrm{mg} / \mathrm{L}$, which means that the reduction level is $94.42 \%$. The 10 volt voltage has a significant effect because the sulfide level becomes $0.033 \mathrm{mg} / \mathrm{L}$ which means that the reduction level is $89.18 \%$. The 5 volt voltage has a significant effect also because the COD level becomes $0.029 \mathrm{mg}$ / $\mathrm{L}$ which means that the reduction level is $90.49 \%$. When viewed from the percentage decrease for both sufida parameters voltage of $5 \mathrm{v}, 10 \mathrm{v}$, and $15 \mathrm{v}$ the difference is not too significant compared to COD where the percentage decrease is quite large.

Tabel 4. The results of the analysis of the influence of time variations

\begin{tabular}{llllll}
\hline & & \multicolumn{4}{c}{ Time (minutes ) } \\
Parameter & Units & & & & \\
& & 10 & & & \\
& & 15 & 20 & 25 & 30 \\
\hline
\end{tabular}

$\begin{array}{lllllll}\mathrm{COD} & \mathrm{mg} / \mathrm{L} & 344.5 & 319.5 & 324.5 & 317 & 284.5\end{array}$

$\begin{array}{lllllll}\text { Sulfide } & \mathrm{mg} / \mathrm{L} & 0.0901 & 0.0803 & 0.0829 & 0.0661 & 0.0859\end{array}$

Table 4 is the result of electrolysis treatment with a time variation with a test voltage of 15 volts, a selection of 15 volt voltage due to tests that have been carried out before carrying out the time variation test and have been described above. Test results on the COD and sulfide parameters occur irregularity. From this it is known that time has a significant effect on COD treatment. Among these time variations (10 minutes, 15 minutes, 20 minutes, 25 minutes and 30 minutes) the 10 minute time gave a decrease in COD level to $344.5 \mathrm{mg} / \mathrm{L}$ which means the level of reduction was $41.21 \%$. Whereas for 15 minutes there was a decrease to $319.5 \mathrm{mg} / \mathrm{L}$ which means that the level of reduction was $45.47 \%$. For a period of 20 minutes there was a decrease to $324.5 \mathrm{mg} / \mathrm{L}$ which means that the level of reduction was $44.62 \%$. Whereas for 25 minutes there was a decrease to 317 $\mathrm{mg} / \mathrm{L}$ which means that the level of reduction was $45.90 \%$. For 30 minutes there was a decrease to 284.5 $\mathrm{mg} / \mathrm{L}$ which means that the level of reduction was $51.45 \%$. From the above results it is known that the greatest decrease in COD parameters occurred in the 30th minute which was $51.45 \%$. As for sulfide levels, for a period of 10 minutes there was a decrease to $0.0901 \mathrm{mg} / \mathrm{L}$ which means that the levels decreased by $70.45 \%$. for 15 minutes there was a decrease to $0.0803 \mathrm{mg} / \mathrm{L}$ which means that the level of reduction was $73.67 \%$. for a period of 20 minutes there was a decrease to $0.0829 \mathrm{mg} / \mathrm{L}$ which means that the level of reduction was $72.81 \%$. for a period of 25 minutes there was a decrease to $0.0661 \mathrm{mg} / \mathrm{L}$ which means that the level of reduction was $78.32 \%$. And for 30 minutes there was a decrease to $0.0859 \mathrm{mg} / \mathrm{L}$, which means the level of decline was $71.83 \%$. It is known that the biggest decrease occurred in the 25 th minute with a decrease in percentage of $78.32 \%$.

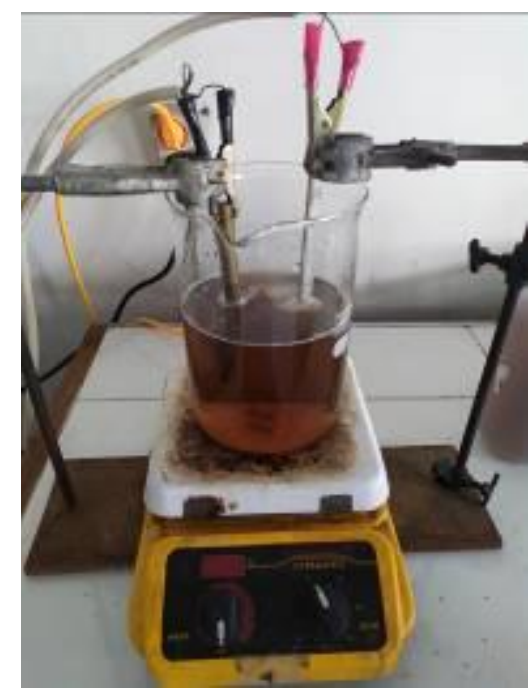

Figure 1. Process of electrolysis

Figure 1 is a process when the waste is processed using the electrolysis method to reduce the parameters of cod and sulfide as well as other parameters by using aluminum as an anode and copper as a cathode with the help of an electric current. This process aims to reduce levels of waste that exist in the ethanol waste.

The electrochemical process is a very attractive method to extirpate just about any pollutant in water and wastewater involving extremely small particles or toxic organic compounds, and it can dissolve even water itself because of the electrochemical characteristic softhese substances. A number of electrochemical processes have been derived to remove deleterious or dispensable constituents in water, for example, electro-oxidation, electrodegradation, electro-coagulation, electroflocculation, electro-Fenton process, and so on (Kim et al., 2013). The process occurs in an electrolyte, a watery or a salt melting solution that gives a possibility to transfer the ions between two electrodes. When an electrical current is applied, the positive ions move to the cathode while the negative ions move to the anode. At the electrodes, the cations are reduced and the anions will be oxidized (Chopra, Kumar Sharma and Kumar, 2011).

Before the electrolysis process is carried out, the waste is given a pretreatment by diluting pure waste with water so that it can be analyzed because pure waste is so concentrated that it hinders the analysis process. dilution is done with a ratio of 1: 500. 


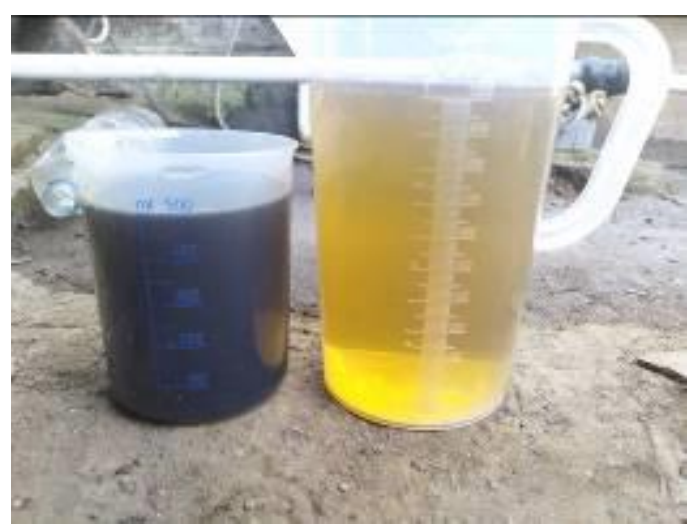

Figure 2. The comparison of pure ethanol waste with ethanol waste after diluting

The picture above illustrates that it is so concentrated in pure waste that it takes time to dilute it with a ratio of 1: 500 until the waste is ready to be tested to determine the content of cod and sulfide. Table 1 is the standard quality of ethanol wastewater issued by the Minister of Environment in the Republic of Indonesia Minister of Environment Regulation number 5 of 2014 concerning the quality standard of wastewater.

\section{CONCLUSION}

From the research and the results of the discussion, the following conclusions are obtained:

First one, The greater the voltage, the more effective it is to reduce COD and sulfide levels, this is evidenced by the results of the 15 volt voltage test which is greater in reducing COD and sulfide levels than the 10 and 5 volt voltages with decreases in COD and sulfide respectively by $27.21 \%$ and $94.42 \%$.

Second one, The longer the treatment time, the more effective it is to reduce COD levels, this is evidenced by the results of the most effective 30 minute time variation test with a decrease of $51.45 \%$

The longer the treatment time does not affect the effectiveness of the decrease in sulfide parameters, this is evidenced by the results of the test that states that the 25 minute time variation is more effective than the 30 minute time variation with a decrease of $78.32 \%$.

\section{REFERENCES}

DE VANCONCELOS, J. N. (2015) "Ethanol Fermentation", Sugarcane: Agricultural Production, Bioenergy and Ethanol, pp. 311-340. doi: 10.1016/B978-0-12-8022399.00015-3

DALENA, F. ET AL. (2019) "Ethanol From Biomass, Ethanol". Elsevier Inc. doi: 10.1016/B978-0-12 811458-2.00002-X.

$\begin{array}{llll}\text { PATEL, } & \text { S. } & \text { AND } & \text { DURGAVATI } \\ \text { VISHWAVIDYALAYA, } & \text { R. }\end{array}$

"Treatment of Distillery Waste Water: A Review", 10(1), pp. 117-139

CHOPRA, A. K., KUMAR SHARMA, A. AND KUMAR, V. (2011) "Overview of Electrolytic treatment: An alternative technology for purification of wastewater", Archives of Applied Science Research, 3(5), pp. 191-206

BURROUGHS, R. and BURROUGHS, R. (2011) "Wastewater". Coastal Governance. 2nd edn. Elsevier Inc. doi: 10.5822/978-161091-016-3_3

CANDIA-ONFRAY, C. ET AL. (2018) "Treatment of winery wastewater by anodic oxidation using BDD electrode", Chemosphere, 206, pp. 709-717. doi: 10.1016/j.chemosphere.2018.04.175

PAKPAHAN, J. E ET AL. (2015) “Analisa Kadar H2S ( Hidrogen Sulfida) dan Keluhan Kessehatan Saluran Pernafasan Serta Keluhan Iritasi Mata pada Masyarakat di Kawasan PT. Allegrindo Nusantara Desa Urung Panei kecamatan Purba Kabupaten Simalungun Tahun 2013", Universitas Sumatera Utara

KIM, D. G. ET AL. (2013) “Agro-industrial wastewater treatment by electrolysis technology", International Journal of Electrochemical Science, 8(7), pp. 98359850. 